\title{
In vivo MRI tracking of iron oxide nanoparticle- labeled human mesenchymal stem cells in limb ischemia
}

This article was published in the following Dove Press journal:

International Journal of Nanomedicine

II March 2013

Number of times this article has been viewed

\author{
Xiang-Xiang $\mathrm{Li}^{1,2, *}$ \\ Kang-An $\mathrm{Li}^{3, *}$ \\ Jin-Bao Qin ${ }^{1,2}$ \\ Kai-Chuang Ye ${ }^{1,2}$ \\ Xin-Rui Yang ${ }^{1,2}$ \\ Wei-Min $\mathrm{Li}^{1,2}$ \\ Qing-Song $\mathrm{Xie}^{4}$ \\ Mi-Er Jiang ${ }^{1,2}$ \\ Gui-Xiang Zhang ${ }^{3}$ \\ Xin-Wu Lu ${ }^{1,2}$ \\ 'Department of Vascular Surgery, \\ Shanghai Ninth People's Hospital \\ Affiliated to Shanghai Jiao Tong \\ University, School of Medicine, ${ }^{2}$ Vascular \\ Center, Shanghai JiaoTong University, \\ ${ }^{3}$ Department of Radiology, Shanghai \\ First People's Hospital, Shanghai Jiao \\ Tong University School of Medicine, \\ Shanghai, People's Republic of China: \\ ${ }^{4}$ Department of Neurosurgery, Cixi \\ Municipal People's Hospital, Zhejiang \\ Province, People's Republic of China \\ *These authors contributed equally to \\ this work
}

Correspondence: Xin-Wu Lu

Department of Vascular Surgery,

Shanghai Ninth People's

Hospital Affiliated to Shanghai

JiaoTong University School of Medicine,

Number 639 Zhi Zao

Ju Road, Shanghai, 2000II,

People's Republic of China

Email luxinwu@yahoo.com.cn

Gui-Xiang Zhang

Department of Radiology, Shanghai

First People's Hospital, Shanghai

Jiaotong University School of Medicine,

Number 100 Haining

Road, Shanghai, 200080,

People's Republic of China

Email guixiangzhang@sina.com
Background: Stem cell transplantation has been investigated for repairing damaged tissues in various injury models. Monitoring the safety and fate of transplanted cells using noninvasive methods is important to advance this technique into clinical applications.

Methods: In this study, lower-limb ischemia models were generated in nude mice by femoral artery ligation. As negative-contrast agents, positively charged magnetic iron oxide nanoparticles (aminopropyltriethoxysilane-coated $\mathrm{Fe}_{2} \mathrm{O}_{3}$ ) were investigated in terms of in vitro labeling efficiency, effects on human mesenchymal stromal cell (hMSC) proliferation, and in vivo magnetic resonance imaging (MRI) visualization. Ultimately, the mice were sacrificed for histological analysis three weeks after transplantation.

Results: With efficient labeling, aminopropyltriethoxysilane-modified magnetic iron oxide nanoparticles (APTS-MNPs) did not significantly affect hMSC proliferation. In vivo, APTSMNP-labeled hMSCs could be monitored by clinical 3 Tesla MRI for at least three weeks. Histological examination detected numerous migrated Prussian blue-positive cells, which was consistent with the magnetic resonance images. Some migrated Prussian blue-positive cells were positive for mature endothelial cell markers of von Willebrand factor and anti-human proliferating cell nuclear antigen. In the test groups, Prussian blue-positive nanoparticles, which could not be found in other organs, were detected in the spleen.

Conclusion: APTS-MNPs could efficiently label hMSCs, and clinical 3 Tesla MRI could monitor the labeled stem cells in vivo, which may provide a new approach for the in vivo monitoring of implanted cells.

Keywords: hind-limb ischemia, magnetic resonance imaging, iron oxide particles, stem cell implant

\section{Introduction}

Recent progress in stem cell labeling with iron oxide particles detectable by magnetic resonance imaging (MRI) has prompted the development of stem cell transplantation therapies for the treatment of various diseases, such as spinal cord injury, ${ }^{1}$ lower-limb ischemia, ${ }^{2}$ myocardial infarction, ${ }^{3}$ and stroke. ${ }^{4}$ Although many approaches have been developed for locating labeled cells, MRI remains a very good noninvasive method that not only has the potential to replicate probing of host organs ${ }^{5}$ without risking radiotoxic damage and other side effects, but also has the advantages of high temporal and spatial resolution to measure multiple physiologic parameters with different pulse sequences.

When implanting stem cells in areas of tissue injury, the implanted cells can release growth factors, improve function, or differentiate into functional cells that 
involve migration, recruitment, and incorporation of cells into tissues. Among many stem cell types, mesenchymal stem cells (MSCs) appear to have many advantages, such as ease of acquisition, multi-lineage differentiation, and secretion of growth factors under the guidance of environmental cues. They can also serve as cellular vehicles and have anti-inflammatory effects by downregulating several immune cell functions, which is very important, especially in an inflammatory microenvironment. In addition, the high resistance of MSCs to starvation stress means that they are less prone to nanoparticle release. ${ }^{6}$ At present, the most common source of MSCs is still bone marrow (BM). ${ }^{7}$

Magnetic nanoparticles, especially superparamagnetic iron oxide particles (SPIOs), have been widely used as agents for labeling stem cells. These nanoparticles have dextran- or siloxane-coated magnetite iron oxide cores and are encapsulated by a polymer or further modified to facilitate internalization. ${ }^{8}$ Although SPIO labeling has many advantages, such as the ability to be tracked by MRI in various tissues ${ }^{9}$ and a high sensitivity, ${ }^{10}$ several studies have reported specific disadvantages. One of the major problems is that they have difficulty remaining in labeled cells in vivo - when they come out, this is termed "leakage" - and the resultant free SPIOs are subjected to endocytosis by macrophages. The other disadvantage is that $50 \%-80 \%$ of the transplanted cells undergo immediate death. Once this occurs, the contrast agents can be transferred to surrounding macrophages in areas of damage and inflammation. Despite the fact that no SPIO-labeled cell has survived for longer than three weeks after transplantation, a significant void area persists in the MRI signal at this time point, which confounds the interpretation of noninvasive cellular imaging or microscopy. ${ }^{11}$

Aminopropyltriethoxysilane (APTS) is a common silane agent with slight toxicity and good biomedical applications, which can be further applied in general bio-conjugation techniques. ${ }^{12}$ Aminopropyltriethoxysilane-modified magnetic iron oxide nanoparticles (APTS-MNPs) - ie, aminopropyltriethoxysilane-coated $\mathrm{Fe}_{2} \mathrm{O}_{3}$ - are positively charged at low $\mathrm{pH}$ but negatively charged at high $\mathrm{pH}^{13}$ and their isoelectric point is 7.2. Most of the particles are quasi-spherical with an average diameter of $10 \mathrm{~nm}$. They have the same size distribution, magnetic properties, and crystal structure as other kinds of magnetic nanoparticles. ${ }^{14}$ As such, in the study reported here, we attempted to label human mesenchymal stem cells (hMSCs) with APTS-MNPs, which are negativecontrast agents.
The purpose of this study was to determine if the APTSMNP-labeled hMSCs could be imaged in vivo, and to observe their short-term (3-week) survival in a lower-limb ischemia model of nude mice.

\section{Materials and methods Isolation and culture of adherent cells from BM}

After informed consent was obtained, normal BM ( $\mathrm{n}=5$; median age 25 years) was harvested from healthy donors and diluted with low-glucose Dulbecco's modified Eagle's medium with $10 \%$ fetal bovine serum (FBS) and $1 \%$ penicillin-streptomycin. A single cell suspension was acquired using a $100 \mu \mathrm{m}$ cell strainer (BD Biosciences, Franklin Lakes, NJ, USA). This suspension was layered on a density gradient cell separation medium (Histopaque ${ }^{\circledR}-1077$, Sigma-Aldrich, St Louis, MO, USA) and centrifuged to isolate the mononuclear cells (MNCs). ${ }^{15}$ After centrifugation, the MNCs that formed a distinct opaque layer were removed from the plasma-Histopaque-1077 interface and washed twice with phosphate-buffered saline (PBS). After this, the MNCs were seeded into six-well culture plates at a density of $1 \times 10^{7} / \mathrm{cm}^{2}$ in Dulbecco's modified Eagle's medium containing $10 \% \mathrm{FBS}$ and $1 \%$ penicillin-streptomycin. The cells were allowed to adhere overnight and maintained at $37^{\circ} \mathrm{C}$ in $5 \% \mathrm{CO}_{2}$. Following this, the non-adherent cells were washed out. Medium changes were carried out three times a week. When the attached cells reached a confluence of between $80 \%$ and $90 \%$, the cultures were trypsinized and passaged at a ratio of $1: 2$.

\section{Phenotypic analysis of hMSCs by flow cytometry}

For phenotypic characterization, surface markers were tested by flow cytometry. The following monoclonal antibodies (mAbs) were used for the immunophenotyping of hMSCs: fluorescein isothiocyanate-conjugated anti-human CD31 and CD73 and phycoerythrin-conjugated anti-human CD29, CD34, CD90, and CD105. The third-passage cells were detached with $0.25 \%$ trypsin-EDTA (Invitrogen, Carlsbad, CA, USA) and washed twice with fluorescence-activated cell-sorting (FACS) buffer (PBS with 2\% FBS). The cell suspension in the FACS buffer was aliquoted per tube and appropriately labeled anti-human antibodies were added then the tubes were incubated for 30 minutes at $4^{\circ} \mathrm{C}$ in the dark. Following incubation, the samples were washed twice 


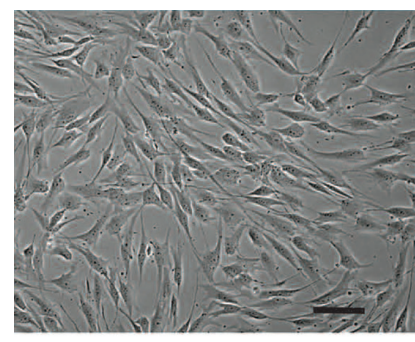

P3 hMSC

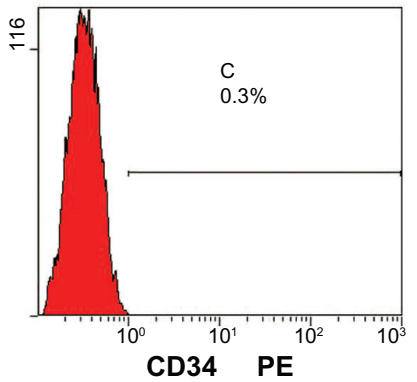

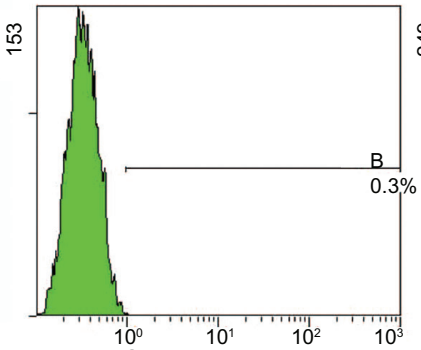

Control

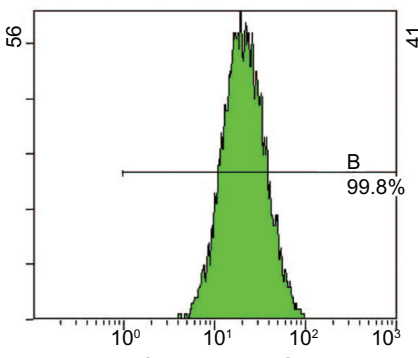

CD73 FITC
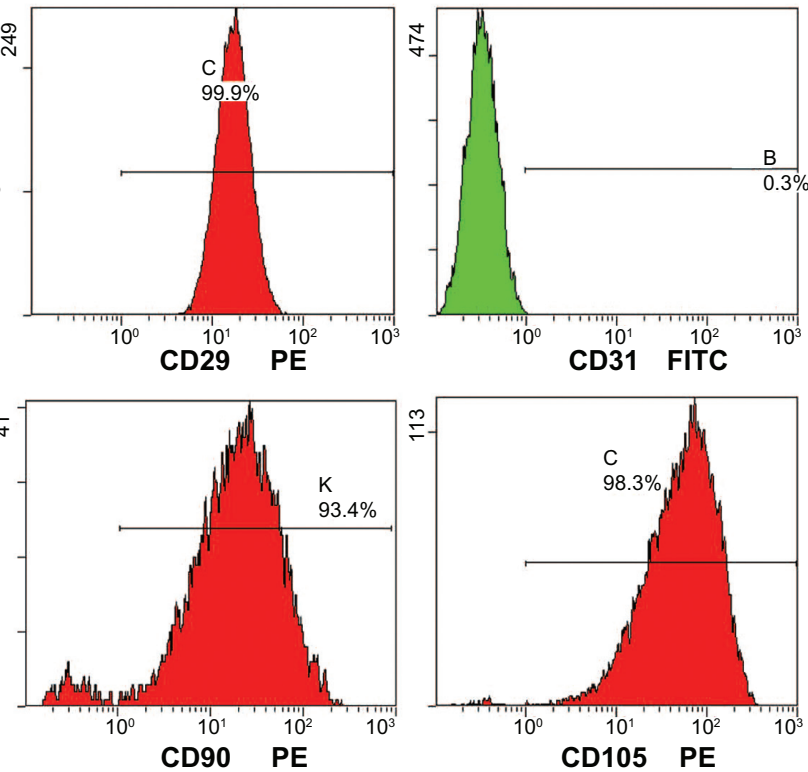

Figure I Morphology and immunophenotypic characterization of human mesenchymal stem cells (hMSCs).

Notes: By flow cytometry, P3 fibroblast-like hMSCs were positive for CD29, CD73, CD90, and CDI05 but negative for CD3I and CD34. The isotype control sample was also negative. Scale bar for photograph $=100 \mu \mathrm{m}$.

Abbreviations: FITC, fluorescein isothiocyanate; PE, phycoerythrin.

with $3 \mathrm{~mL}$ of FACS buffer and centrifuged for 3 minutes at $1800 \mathrm{rpm}$. The cells were resuspended with FACS buffer before being analyzed using a flow cytometer (Epics Altra, Beckman Coulter, Fullerton, CA, USA). The collected data were analyzed by the CXP software 7.3 (Beckman Coulter).

\section{Cell labeling and Prussian blue staining}

APTS-MNPs were prepared as reported previously. ${ }^{16}$ The third-passage hMSCs $\left(5 \times 10^{5}\right)$ were incubated with different concentrations of APTS-MNPs $(0,12.5,25$, and $50 \mu \mathrm{g} / \mathrm{mL})$ at $37^{\circ} \mathrm{C}$ in $5 \% \mathrm{CO}_{2}$ for 12,24 , and 48 hours, respectively. To improve incorporation, $0.75 \mu \mathrm{g} / \mathrm{mL}$ polyamine poly-1lysine (PLL) hydrobromide (Sigma-Aldrich) was added into the medium 1 hour before cell incubation, according to our previous methods. ${ }^{17}$ After that, adherent cells were repeatedly washed with fresh changes of PBS to remove loosely attached or extracellular particles until the PBS appeared free of particles under light microscopy. For the Prussian blue staining of the intracellular iron particles, a small portion of labeled cells was washed three times with PBS to remove excess APTS-MNPs and incubated with $2 \%$ potassium ferrocyanide (Perl's reagent) in $6 \%$ hydrochloric acid for 30 minutes. After another wash, the cells were counterstained with nuclear fast red and observed under a microscope. All images were digitally recorded and the numbers of Prussian blue-positive cells in five random fields were calculated.
The images were processed with Image-Pro Plus 6.0 (Media Cybernetics, Rockville, MD, USA).

\section{Transmission electron microscopy (TEM) study}

For TEM analysis, the labeled cells were fixed with 3\% buffered glutaraldehyde overnight at $48^{\circ} \mathrm{C}$. After incubation in $1 \%$

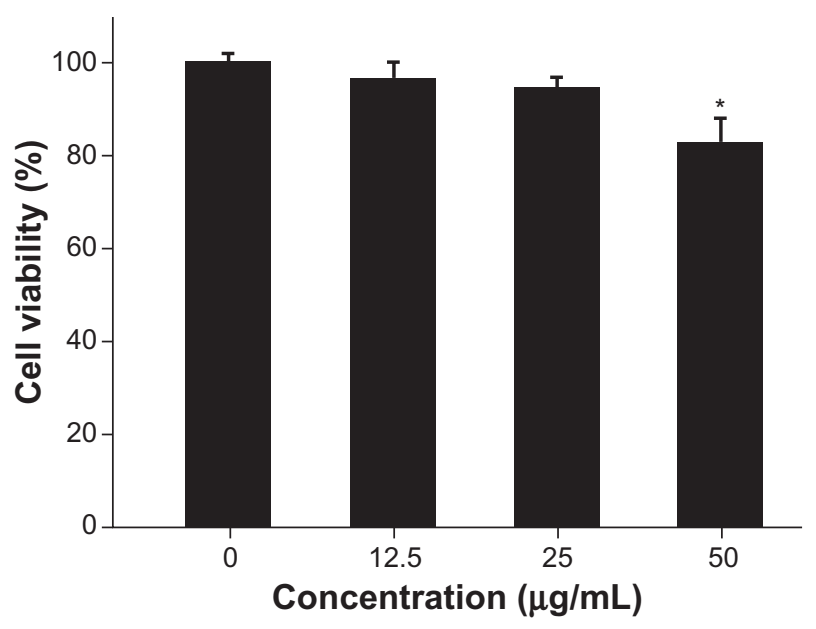

Figure 2 The viability of human mesenchymal stem cells incubated with $0,12.5$, 25 , and $50 \mu \mathrm{g} / \mathrm{mL}$ of aminopropyltriethoxysilane-modified magnetic iron oxide nanoparticles (APTS-MNPs).

Notes: MTT assay demonstrated that the cell viability was not significantly affected $(P>0.05)$ until the concentration of APTS-MNPs reached $50 \mu \mathrm{g} / \mathrm{mL}(P<0.05)$. Cell activity was up to $95 \%$ at APTS-MNP concentrations of $25 \mu \mathrm{g} / \mathrm{mL}$ and above.

Abbreviation: MTT, 3-(4,5-dimethylthiazol-2-yl)-2,5-diphenyltetrazolium bromide. 


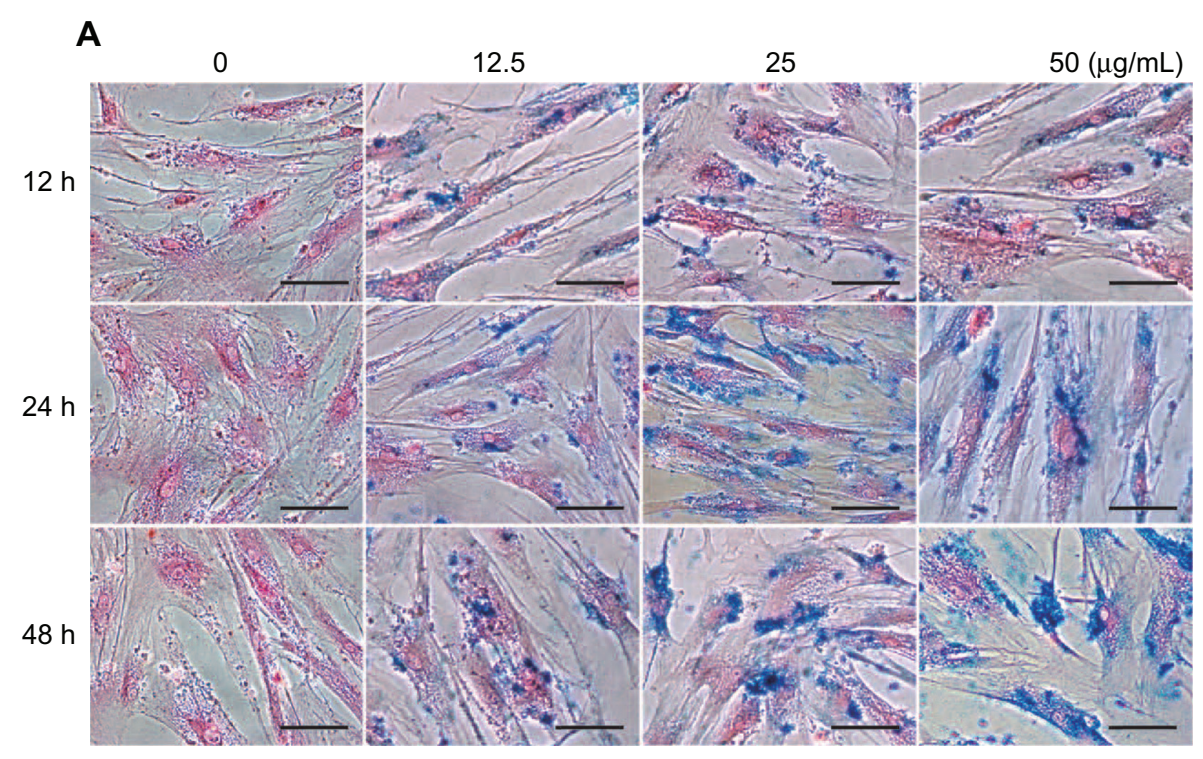

B

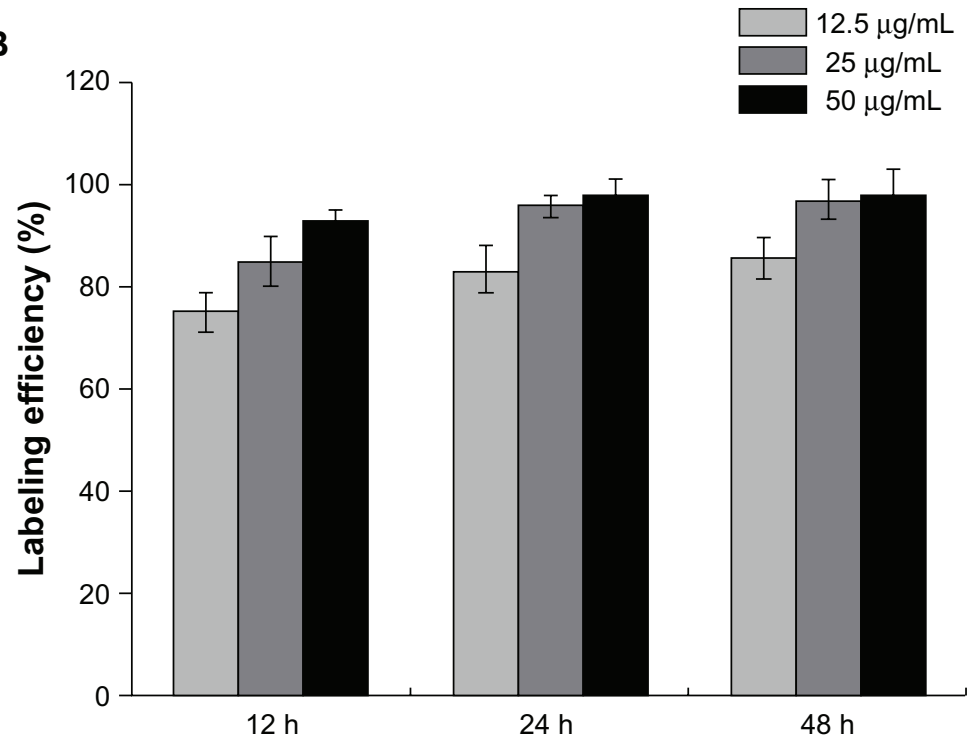

Figure 3 Labeling efficiency of aminopropyltriethoxysilane-modified magnetic iron oxide nanoparticles (APTS-MNPs) on human mesenchymal stem cells (hMSCs). Cells were labeled with $0,12.5,25$, and $50 \mu \mathrm{g} / \mathrm{mL}$ of APTS-MNPs for 12,24, and 48 hours, respectively. (A) Prussian blue stain showed an increase of iron accumulation in the hMSCs by elevating APTS-MNP concentrations or extending incubation time. (B) Quantitative analysis using $0.75 \mu \mathrm{g} / \mathrm{mL}$ polyamine poly-l-lysine hydrobromide showed over $95 \%$ of hMSCs were efficiently labeled by concentrations of APTS-MNPs of $25 \mu \mathrm{g} / \mathrm{mL}$ and above for 24 hours.

Note: Scale bar in $A=200 \mu \mathrm{m}$.

osmium tetroxide for 1 hour, the labeled cells were dehydrated in a concentration gradient of ethanol then embedded in artificial resin (Epon; Merck, Darmstadt, Germany). The samples were sliced into ultrathin sections $(60 \mathrm{~nm})$. Thin sections of cells embedded in artificial resin were evaluated to prevent falsepositive findings then examined with an EM $10 \mathrm{CR}$ electron microscope (Carl Zeiss, Oberkochen, Germany) at 60-80 kV.

\section{Assessment of cell proliferation}

The proliferation of APTS-MNP-labeled hMSCs was examined by 3-(4,5-dimethylthiazol-2-yl)-2,5-diphenyltetrazolium bromide (MTT) assay. The cells were plated on 96-well plates $\left(2 \times 10^{3}\right.$ cells/well $)$ and co-cultured with different concentrations of APTS-MNPs $(0,12.5,25$, and $50 \mu \mathrm{g} / \mathrm{mL})$. After the cells were incubated with MTT (Sigma-Aldrich; $5 \mathrm{mg} / \mathrm{mL}$ in PBS) at $37^{\circ} \mathrm{C}$ and $5 \% \mathrm{CO}_{2}$ for 24 hours, cultures were washed with PBS for three times to remove residual APTSMNPs and lysed by adding $200 \mu \mathrm{L}$ of dimethyl sulfoxide. The optical density was measured at $490 \mathrm{~nm}$.

\section{Animal models and hMSC transplantation}

Male nude mice $(n=12)$ aged 7 weeks old were obtained from the Shanghai SLAC Laboratory Animal Company (Shanghai, People's Republic of China). All animal protocols 


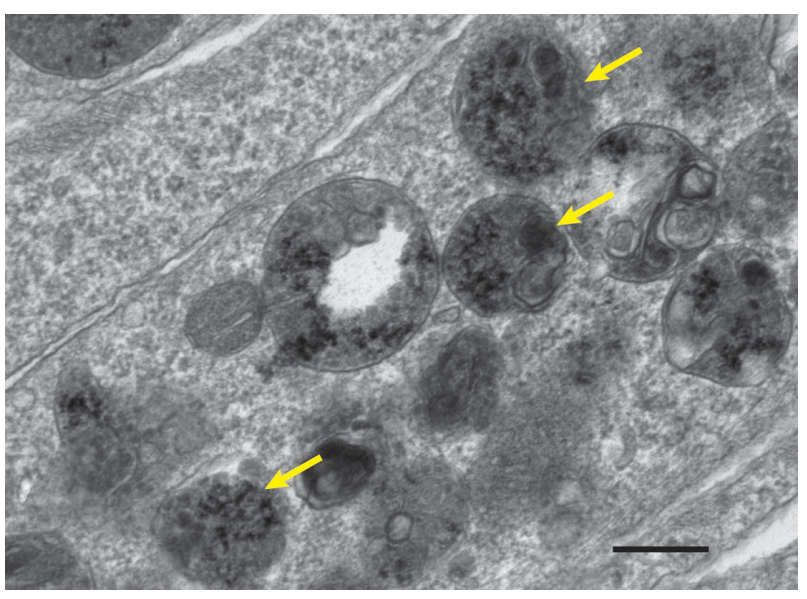

Figure 4 Transmission electron microscopy image showing nanoparticles accumulated in the endosomes/lysosomes (arrows).

Note: Scale bar $=0.5 \mu \mathrm{m}$.

were approved by the Animal Experiment and Care Committee of the Shanghai Jiao Tong University School of Medicine. The mice were anesthetized with chloral hydrate $(10 \mathrm{mg} / \mathrm{kg})$. The left femoral arteries were excised from their proximal origin as a branch of the external iliac artery to the distal point where they bifurcate into the popliteal arteries. The skin was closed with single sutures using 5/0 silk. Following the induction of arterial injury, either $2 \times 10^{6}$ unlabeled (Control) or labeled (Test) hMSCs were engrafted by intramuscular injection. Paled skin with decreased temperature and intermittent claudication was observed in the left hind legs after arterial occlusion, but no symptoms of ulcer or gangrene were observed throughout the study.

\section{In vivo $M R I$ measurements}

The nude mice were imaged under general anesthesia 3, 10, and 21 days postsurgery to assess the detection, migration, and retention of the transplanted stem cells. Two-dimensional T2-weighted MRI was obtained using a Signa HDxt 3.0T superconductor clinical magnetic resonance system (GE Medical Systems, Milwaukee, WI, USA) with a custom-built rodent receiver coil (Chenguang Med Tech, Shanghai, People's Republic of China). The following parameters were used for the T2-weighted imaging: repetition time $(\mathrm{TR})=2500 \mathrm{~ms}$, echo time $(\mathrm{TE})=81.9 \mathrm{~ms}$, resolution $=256 \times 256$, section thickness $=2.0 \mathrm{~mm}$, and field of view $(\mathrm{FOV})=60 \times 60 \mathrm{~mm}$.
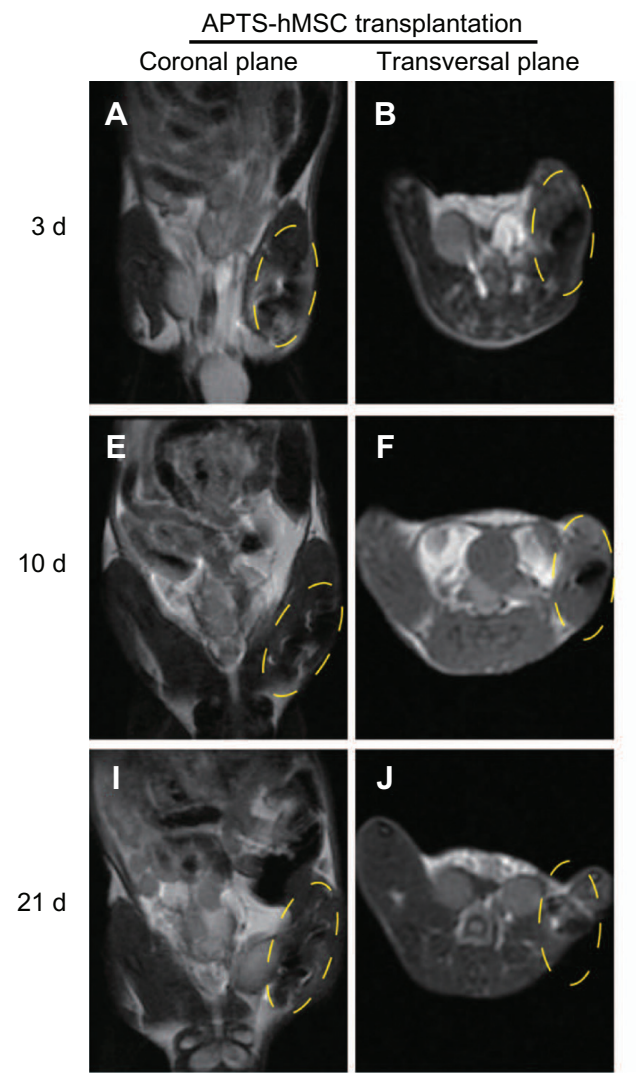
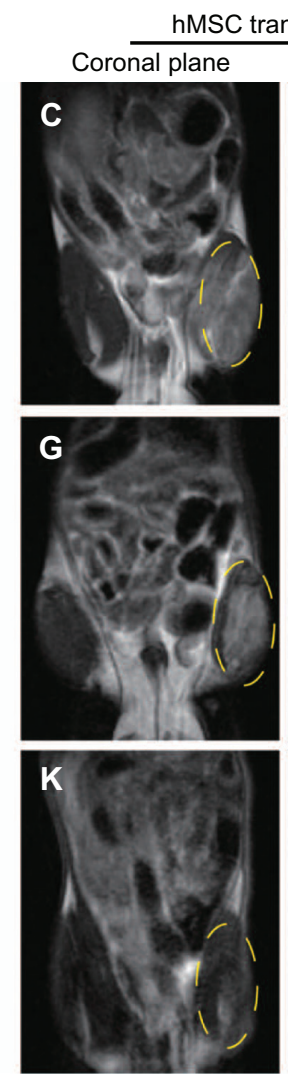
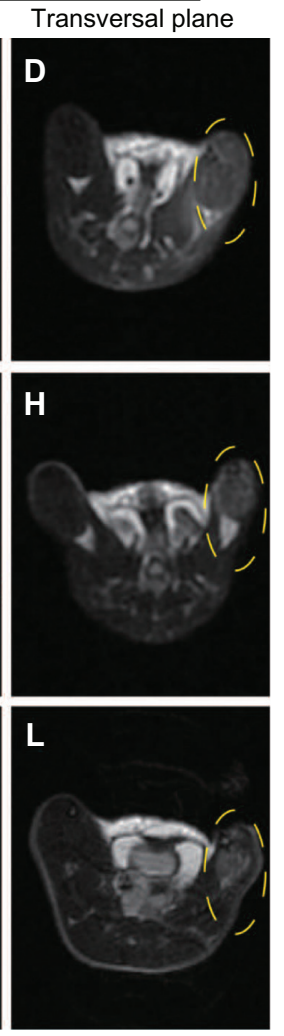

Figure 5 After intramuscular injection in the ischemic limb models, sequences of 3 Tesla magnetic resonance images were obtained at 3 , I0, and 21 days in coronal and transversal planes. The transplanted human mesenchymal stem cells (hMSCs) in the left legs (circled) at 3 days (A-D), I0 days (E-H), and 21 days (I-L) after transplantation.

Abbreviation: APTS, aminopropyltriethoxysilane. 


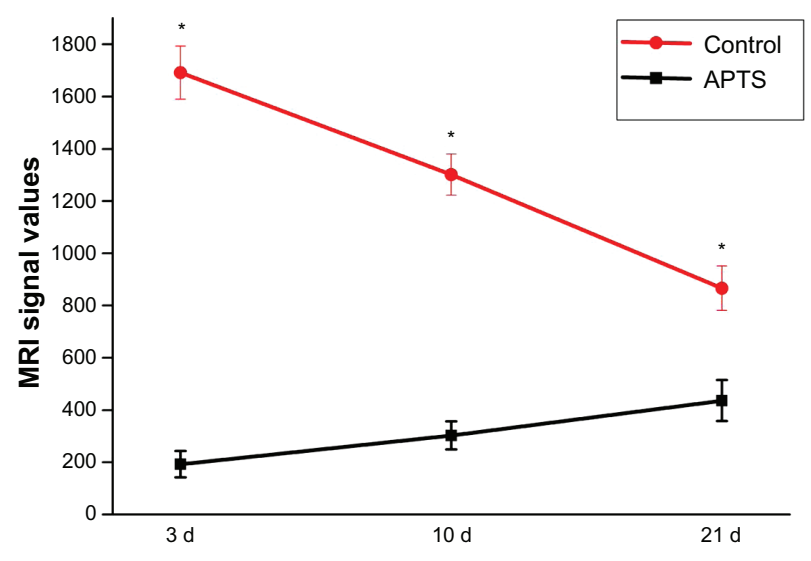

Figure 6 Magnetic resonance imaging (MRI) signal values revealed a statistically significant $(P<0.05)$ change over time in both groups.

Notes: In the test groups, the signal levels progressively increased after transplantation. However, in the control groups, the MRI signal values gradually reduced over time.

Abbreviation: APTS, aminopropyltriethoxysilane.

\section{Histological analysis}

For histological analysis, the mice were sacrificed 3 weeks after transplantation. The muscle with adjacent tissue was carefully dissected from the injection site and fixed with $4 \%$ paraformaldehyde for 5 days at $4^{\circ} \mathrm{C}$. The samples were embedded with an optimum cutting temperature compound (OCT, Tissue-Tek, Torrance, CA, USA) and cut into sections $(8 \mu \mathrm{m})$ with a cryostat. The sections were serially collected on gelatin-coated glass slides, stained with hematoxylin and eosin. Prussian blue staining was performed to detect APTS-labeled MSCs. Mature endothelial cell-specific marker (von Willebrand factor [VWF]), anti-human proliferating cell nuclear antigen (PCNA), and macrophage (F4/80) staining were used according to our previous protocols to observe the fate of transplanted cells. ${ }^{17}$

Other organs were also removed from the sacrificed mice and stained, including the liver, spleen, and kidneys, to carefully validate the distribution of labeled cells in vivo.

\section{Statistical analysis}

All data presented are expressed as means \pm standard deviation. For quantitative comparison and analysis, the values were analyzed using one-way analysis of variance with a $t$-test. A $P$ value of $<0.05$ was considered significant.

\section{Results}

\section{Characterization of hMSCs} Immune phenotype

Fibroblast-like hMSCs (Figure 1) were extensively expanded and characterized by flow cytometry. The results showed that passage $3 \mathrm{hMSCs}$ were positive for CD29, CD73, CD90, and CD105, which is consistent with the findings for hMSCs in the literature, ${ }^{18}$ but negative for CD31 and CD34 (Figure 1), indicating that these cells were not of hematopoietic origin.

\section{In vitro uptake of APTS-MNPs into hMSCs and viability}

MTT assay demonstrated that cell viability was not significantly affected $(P>0.05)$ until the concentration of APTS-MNPs reached $50 \mu \mathrm{g} / \mathrm{mL}(P<0.05)$. Cell activity reached $95 \%$ at a APTS-MNP concentration of $25 \mu \mathrm{g} / \mathrm{mL}$ (Figure 2). Prussian blue stain showed increasing iron accumulation in the hMSCs as APTS-MNP concentration or incubation time was increased (Figure 3A). Quantitative analysis showed over $95 \%$ of hMSCs were efficiently labeled by $25 \mu \mathrm{g} / \mathrm{mL}$ APTS-MNPs at 24 hours when $0.75 \mu \mathrm{g} / \mathrm{mL}$ polyamine PLL hydrobromide was used (Figure 3B). As such, we chose $25 \mu \mathrm{g} / \mathrm{mL}$ as a safe and efficient concentration with which to label hMSCs. TEM results revealed that the APTS-MNPs accumulated in the endosomes/lysosomes (arrows, Figure 4).

\section{In vivo tracking of labeled hMSCs}

On magnetic resonance images of ischemia limb and ipsilateral injected cells, the APTS-MNP-labeled cells could be clearly detected as hypo-intense areas of about $2-3 \mathrm{~mm}$ around the point of transplantation corresponding to the injection sites (Figure 5A and B), compared with high signals in the control samples (Figure 5C and D). In the test groups, although the hypo-intense regions were gradually shrinking in the transversal planes, the signal reduction area extended further by $1-2 \mathrm{~mm}$ in coronal planes (Figure 5I) and persisted at the end of the experiment (Figure 5J). In the control groups, a small region of high signal could be detected after 21 days (Figure 5L). Nevertheless, MRI signal values showed a statistically significant $(P<0.05)$ change over time in both groups (Figure 6).

\section{Histological analysis}

Animals were harvested to correlate MRI findings with histologic evidence. Migratory Prussian blue-positive cells were detected in tissue sections (Figure 7A and B), which matched the magnetic resonance images. Further immunofluorescence staining with VWF and F4/80 was performed to exclude this phenomenon, which resulted from the presence of local macrophages loaded with iron, and investigate the fate of the labeled cells. The VWF staining results confirmed that many migratory Prussian blue-positive cells were also positive for VWF and anti-human PCNA (Figure 7D-F), and these cells were healthy on 4',6-diamidino-2-phenylindole (DAPI) staining in the nucleus (Figure 7G-I). F4/80 staining revealed that the macrophage infiltration was mostly 

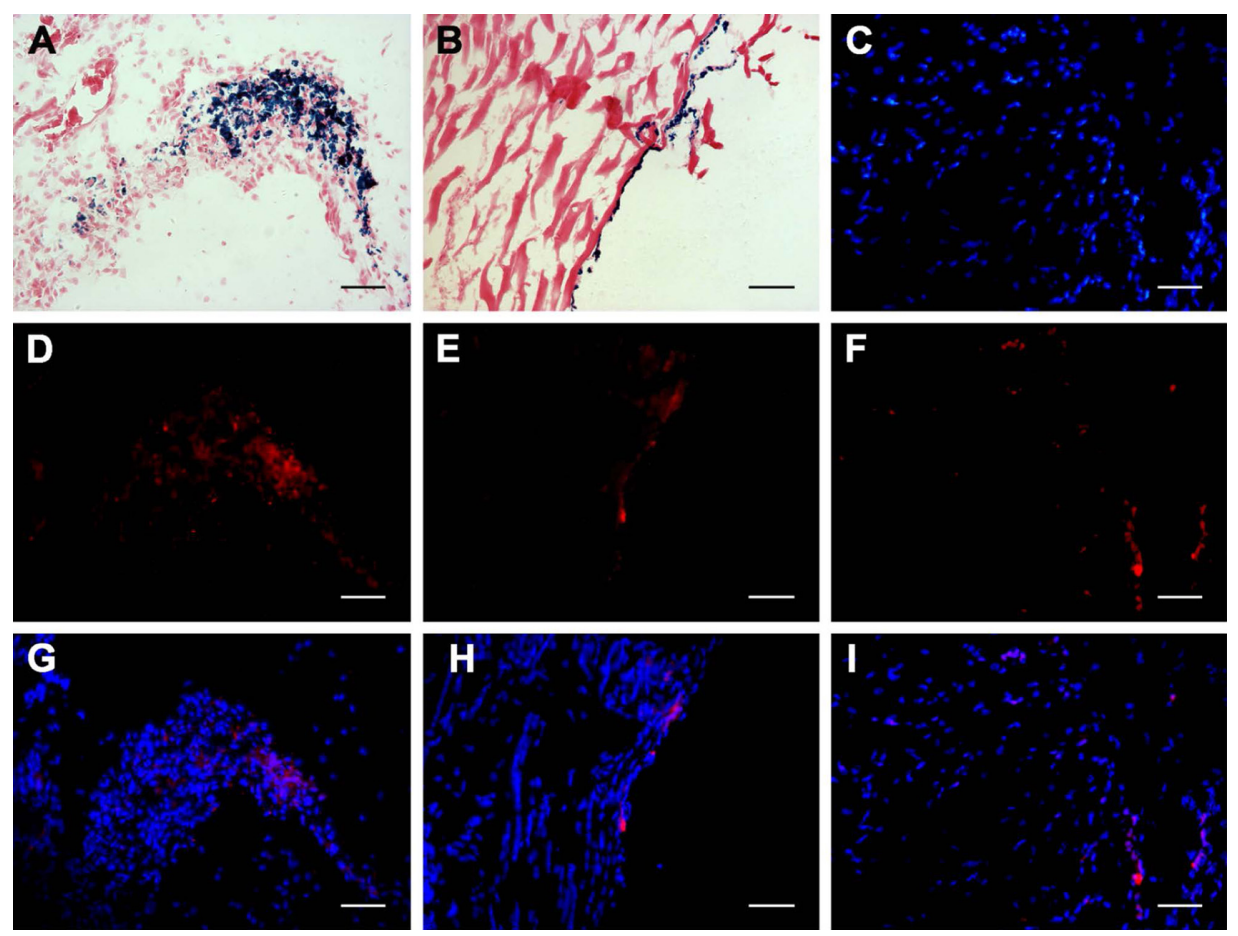

Figure 7 Prussian blue staining and mature endothelial cell-specific markers (von Willebrand factor [VWF]) immunostaining of labeled human mesenchymal stem cells at 21 days after implantation. ( $\mathbf{A}$ and $\mathbf{B}$ ) Prussian blue staining revealed there were numerous migrating iron-containing cells, as was demonstrated in the magnetic resonance images. Fluorescent staining revealed that some migrated Prussian blue-positive cells were positive for VWF (D and $\mathbf{E})$ and anti-human proliferating cell nuclear antigen (F). These cells were healthy, with DAPI staining in the nucleus (C), merged DAPI and cellular staining (G-I).

Notes: Scale bars $=100 \mu \mathrm{m}(\mathbf{B})$ and $50 \mu \mathrm{m}(\mathbf{A}$ and $\mathbf{C}-\mathbf{I})$.

Abbreviation: DAPI, 4',6-diamidino-2-phenylindole.

present at the center of the Prussian blue staining region, not at the boundary (Figure $8 \mathrm{C}$ ). However, in some areas, F4/80 revealed there were few macrophages (Figure 8D).

Other organs were also removed from the sacrificed mice and stained with hematoxylin and eosin and Prussian blue to observe the distribution of labeled cells in vivo (Figure 9). Prussian blue-positive nanoparticles, which could not be found in other organs, were detected in the spleen in the test groups (Figure 9F).

\section{Discussion}

As cell transplant therapies are being explored in various animal models of disease, interest in noninvasive tracking methods is rapidly growing. In the past, three approaches were used to label exogenous cells: exogenous gene transfection, DNA markers, and nuclear staining. However, these methods cannot provide dynamic tracer data without sacrificing animals. Therefore, a better and more practical method for tracking transplanted cells in vivo is needed. MRI is an attractive tool with which to detect transplanted cells in living organisms with high spatiotemporal, repeated, and noninvasive visualization because of its ability to image in real-time in vivo.
As promising contrast agents, magnetic iron oxides are suitable for labeling transplanted cells and allow the cells to be repeatedly imaged within the tissue by MRI. ${ }^{2}$ Moreover, commercially-available ferumoxides consisting of dextrancoated SPIO nanoparticles with high negative charges have been widely used to label cells. When used alone, however, ferumoxides do not efficiently label non-phagocytic cells without modifying nanoparticle-surface charges. Therefore, polycationic transfection agents should be used to enhance membrane permeability. ${ }^{5}$

The modification of APTS endows magnetic iron oxide nanoparticles with excellent water dispersibility, colloidal stability, and positive charge. ${ }^{19}$ Although many studies examining APTS-MNPs have been reported, ${ }^{14,16,20,21}$ few report on APTS-MNPs in their in vivo experiments. Therefore, we used the traditional methods of the addition of polyamine hydrobromide and MTT assay to facilitate the incorporation of nanoparticles and measure cell proliferation, respectively. In the present study, MTT assay demonstrated the cell viability was not significantly affected $(P>0.05)$ until the APTS-MNPs concentration reached $50 \mu \mathrm{g} / \mathrm{mL}(P<0.05)$. Therefore, we chose a concentration of $25 \mu \mathrm{g} / \mathrm{mL}$ to label the hMSCs safely. This finding was consistent with other 

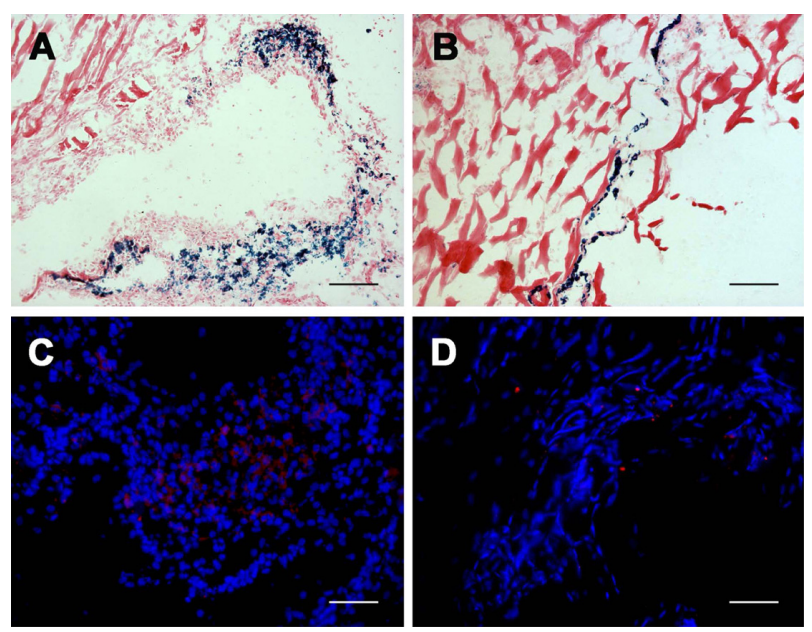

Figure 8 Prussian blue staining and macrophage staining (F4/80) of labeled human mesenchymal stem cells 21 days after implantation. (A and B) Prussian blue staining revealed there were numerous migrating iron-containing cells, as was demonstrated in the magnetic resonance images. (C) Immunofluorescence results confirmed that some Prussian blue-positive cells also expressed F4/80, which was mostly present at the center rather than the boundary of the Prussian blue-stained areas. (D) However, in some areas, $\mathrm{F} 4 / 80$ revealed there were few macrophages.

Notes: Scale bars $=100 \mu \mathrm{m}(\mathbf{A})$ and $50 \mu \mathrm{m}(\mathbf{B}-\mathbf{D})$.

Abbreviation: hMSCs, human mesenchymal stem cells.

kinds of iron oxide ${ }^{4}$ and proof of the nanoparticles' utility as a cellular labeling agent for MRI tracking.

The mechanisms of endocytotic uptake differ according to particle size. For example, particles of 50-200 nm are taken up by cells through a clathrin-mediated pathway. With increasing size, caveolae-mediated internalization becomes more obvious, and this is the predominant pathway of entry for particles of $500 \mathrm{~nm}$ in size..$^{22}$ In this research, the incubation of hMSCs resulted in APTS-MNPs residing in the cytoplasm within membrane-bound vesicles, which suggested an endocytotic uptake mechanism previously described for iron oxides. ${ }^{23}$ We have already shown that iron oxide nanoparticle-labeled cells led to signal hypo-intensities in T2-weighted MRI, compared with the surrounding white matter in vitro. ${ }^{16}$ Accordingly, we speculated that the reduced signal could be attributed to the presence of APTS-MNPlabeled cells, which was histologically confirmed after in vivo imaging.

In this study, we noticed that MRI could detect these distant migrated cells to a certain degree, showing a mild change of contour and an elongated shape. Nevertheless, others have previously proposed that SPIO-labeled cells, which were detected further away from the injection site, are usually negative for the contrast agent. ${ }^{24,25}$ In the control groups, a smaller reduction in signal intensity was observed. The most likely explanation for this was the presence of iron-containing hemosiderin and deoxyhemoglobin that decomposed from trauma-induced small hematoma or operation-induced hemorrhage. ${ }^{26}$

Numerous studies have demonstrated that MRI of iron-labeled cells allows for their detection after transplantation. ${ }^{27,28}$ However, signal hypo-intensities may not reliably represent the original donor cells. Thus, cell death and subsequent engulfment of iron particles by macrophages may confound the interpretation of noninvasive cellular imaging. Moreover, a previous study revealed that no hMSCs survived three weeks after transplantation, despite the fact that hMSCs are
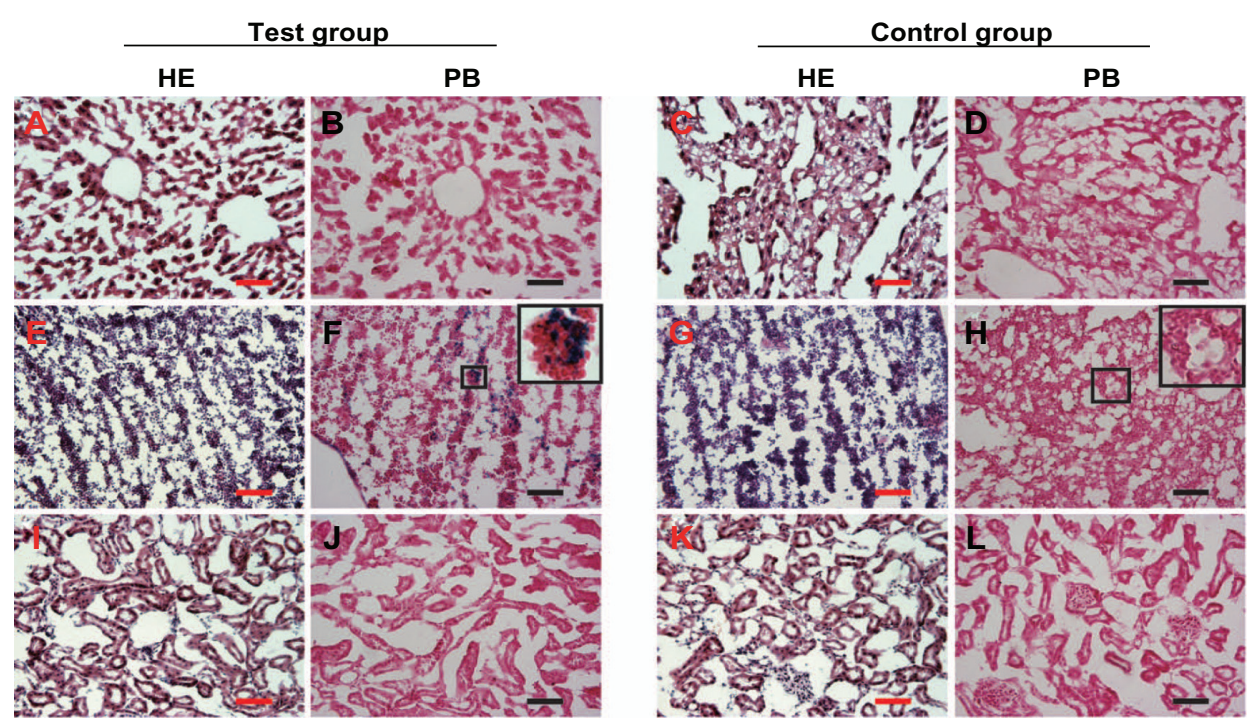

Figure 9 Liver (A-D), spleen (E-H), and kidneys (I-L) were also removed from the sacrificed mice, stained with hematoxylin and eosin (HE) and Prussian blue (PB) (Figure 6).

Notes: Prussian blue-positive nanoparticles were detected in the spleen in the test groups (Figure 6F). Scale bars $=50 \mu \mathrm{m}$. 
relatively immunoprivileged. ${ }^{29}$ In the present study, however, we demonstrated that the elongated shape present on MRI was more likely to represent the migration of APTS-MNP-labeled hMSCs, because histologic examination showed that Prussian blue-positive cells, which migrated longer distances from the point of injection, did not express macrophage marker F4/80. This result was consistent with other studies in which $<10 \%$ of the total iron from FE-Pro-labeled MSCs was found in the activated macrophages, ${ }^{11}$ and the data corroborate the idea that stress signals in lesioned tissue could induce MSCs to produce more anti-inflammatory factors. ${ }^{30}$ Therefore, the contribution of iron-containing macrophages to the hypo-intense regions observed in an area of magnetically labeled cells would be considered minimal. ${ }^{11}$

Further, different methods of transplantation yielded varied cell viabilities. In our limb ischemia model, the contrast agent-labeled cells were directly injected through the needle, which did not cause a significant amount of cell death and ensured that the contrast agent concentration remained relatively high in the evaluated field of view. This method was distinct from intravenous injection, in which cells passed through many intermediate organs, including several immune organs, before reaching their final destination.

However, F4/80-positive staining was still present in some areas, especially at the center of the Prussian blue staining regions. There are several reasons for this phenomenon. First, some studies have demonstrated that the direct transplantation of stem cells into target tissues results in the death of a percentage of the donor cells, ${ }^{31,32}$ which may happen more often at the center of transplanted cells because of the lack of culture medium, as in a three-dimensional cell culture. Subsequently, macrophages may phagocytose dead cells and iron particles, which may become secondarily iron labeled. ${ }^{33}$ Second, cell viability was different after transplantation, which was due to the different injection sites. ${ }^{34}$ Finally, although we used PBS to remove loosely attached or extracellular particles, it is possible that a small amount of iron particles was attached to the surface of the labeled cells.

During the recovery of the ischemic tissue, reciprocal crosstalk and interaction between the implant and host tissue were crucial. The fate of implanted cells in the host tissue was affected by chemical and physical factors in the microenvironment, such as the concentration gradient of chemoattractants ${ }^{35}$ and the vascular network within implants to supply oxygen. ${ }^{36}$ We noted that many migratory Prussian blue-positive cells were positive for VWF staining, and the results were in accordance with previous studies in that the migrated hMSCs differentiated into vascular endothelial cells, which were positive for VWF. ${ }^{37,38}$

Nevertheless, there were several limitations in this preliminary study. First, we did not examine the multi-potency ability of APTS-MNP-labeled MSCs in vitro. Second, the MRI of the APTS-MNP-labeled hMSCs in vitro needed further investigation in terms of the characteristics of the magnetic nanoparticles. Further, the fate of the APTS-MNPlabeled cells requires in-depth analysis after longer-term tracing. However, these will be experimentally tested in our future research.

\section{Conclusion}

Ultimately, this study demonstrated that hMSCs labeled with APTS-MNPs at a concentration of $25 \mu \mathrm{g} / \mathrm{mL}$ could be detected in vivo, having the potential to be used for various biomedical applications. Their low toxicity may make them useful for localization of the transplanted stem cells over a long period. The extension of the lowsignal region could not be attributed to iron-laden macrophages. After three weeks, histological analysis results demonstrated that a certain number of transplanted cells survived in the ischemic region and some of these cells differentiated into vascular endothelial cells, which were positive for VWF.

Thus, this study has made a step forward in understanding the MRI trace of magnetic nanoparticles in vivo.

\section{Acknowledgments}

This work was supported by the National Natural Science Foundation of China (30772104); the Natural Science Foundation of Shanghai Science and Technology Committee (11ZR1429300); the Medical Guiding Program of Shanghai Science and Technology Committee (1141190800); the Songjiang Medical Climbing Program, Shanghai, People's Republic of China (2011PD04); and the Ningbo Natural Science Foundation (2008A610093).

The authors appreciate the kind support of Professor Qing-song Xie, Wei Liu, Jing-jun Chen, De-min Yin, Li-juan Zong, Juan-juan Wu, and Wan-yao Xia. Qing-song Xie kindly provided the iron oxide nanoparticles used in this study.

\section{Disclosure}

The authors report no conflicts of interest in this work.

\section{References}

1. Vaněček V, Zablotskii V, Forostyak S, et al. Highly efficient magnetic targeting of mesenchymal stem cells in spinal cord injury. Int $J$ Nanomedicine. 2012;7:3719-3730. 
2. Agudelo CA, Tachibana Y, Noboru T, et al. Long-term in vivo magnetic resonance imaging tracking of endothelial progenitor cells transplanted in rat ischemic limbs and their angiogenic potential. Tissue Eng Part A. Aug 2011;17(15-16):2079-2089.

3. Li Y, Yao Y, Sheng Z, Yang Y, Ma G. Dual-modal tracking of transplanted mesenchymal stem cells after myocardial infarction. Int $J$ Nanomedicine. 2011;6:815-823.

4. Lee ES, Chan J, Shuter B, et al. Microgel iron oxide nanoparticles for tracking human fetal mesenchymal stem cells through magnetic resonance imaging. Stem Cells. 2009;27(8):1921-1931.

5. Jendelová P, Herynek V, Urdzíková L, et al. Magnetic resonance tracking of transplanted bone marrow and embryonic stem cells labeled by iron oxide nanoparticles in rat brain and spinal cord. J Neurosci Res. 2004;76(2):232-243.

6. Silva AK, Wilhelm C, Kolosnjaj-Tabi J, Luciani N, Gazeau F. Cellular transfer of magnetic nanoparticles via cell microvesicles: impact on cell tracking by magnetic resonance imaging. Pharm Res. 2012;29(5): 1392-1403.

7. Lee OK, Kuo TK, Chen WM, Lee KD, Hsieh SL, Chen TH. Isolation of multipotent mesenchymal stem cells from umbilical cord blood. Blood. 2004;103(5):1669-1675.

8. Rogers WJ, Meyer CH, Kramer CM. Technology insight: in vivo cell tracking by use of MRI. Nat Clin Pract Cardiovasc Med. 2006;3(10):554-562.

9. Andreas K, Georgieva R, Ladwig M, et al. Highly efficient magnetic stem cell labeling with citrate-coated superparamagnetic iron oxide nanoparticles for MRI tracking. Biomaterials. 2012;33(18):4515-4525.

10. Masuda $\mathrm{C}$, Maki Z, Morikawa S, et al. MR tracking of transplanted glial cells using poly-L-lysine-CF3. Neurosci Res. 2006;56(2):224-228.

11. Pawelczyk E, Arbab AS, Chaudhry A, Balakumaran A, Robey PG, Frank JA. In vitro model of bromodeoxyuridine or iron oxide nanoparticle uptake by activated macrophages from labeled stem cells: implications for cellular therapy. Stem Cells. 2008;26(5):1366-1375.

12. Tang T, Fan H, Ai S, Han R, Qiu Y. Hemoglobin (Hb) immobilized on amino-modified magnetic nanoparticles for the catalytic removal of bisphenol A. Chemosphere. 2011;83(3):255-264.

13. Hwang W, Kim BH, Dandu R, Cappello J, Ghandehari H, Seog J. Surface Induced nanofiber growth by self-assembly of a silk-elastin-like protein polymer. Langmuir. 2009;25(21):12682-12686.

14. Zhang S, Chen X, Gu C, et al. The effect of iron oxide magnetic nanoparticles on smooth muscle cells. Nanoscale Res Lett. 2009;4(1):70-77.

15. Pittenger MF, Mackay AM, Beck SC, et al. Multilineage potential of adult human mesenchymal stem cells. Science. 1999;284(5411):143-147.

16. Ma M, Zhang Y, Yu W, Shen HY, Zhang HQ, Gu N. Preparation and characterization of magnetite nanoparticles coated by amino silane. Colloids Surf A Physicochem Eng Asp. 2003;212(2-3):219-226.

17. Qin JB, Li KA, Li XX, et al. Long-term MRI tracking of dual-labeled adipose-derived stem cells homing into mouse carotid artery injury. Int J Nanomedicine. 2012;7:5191-5203.

18. Oswald J, Boxberger S, Jørgensen B, et al. Mesenchymal stem cells can be differentiated into endothelial cells in vitro. Stem Cells. 2004;22(3):377-384.

19. Shen M, Cai H, Wang X, et al. Facile one-pot preparation, surface functionalization, and toxicity assay of APTS-coated iron oxide nanoparticles. Nanotechnology. 2012;23(10):105601.

20. Netto CG, Nakamatsu EH, Netto LE, et al. Catalytic properties of thioredoxin immobilized on superparamagnetic nanoparticles. J Inorg Biochem. 2011;105(5):738-744.

21. Yang C, Rait A, Pirollo KF, Dagata JA, Farkas N, Chang EH. Nanoimmunoliposome delivery of superparamagnetic iron oxide markedly enhances targeting and uptake in human cancer cells in vitro and in vivo. Nanomedicine. 2008;4(4):318-329.
22. Rejman J, Oberle V, Zuhorn IS, Hoekstra D. Size-dependent internalization of particles via the pathways of clathrin- and caveolae-mediated endocytosis. Biochem J. 2004;377(Pt 1):159-169.

23. Matuszewski L, Persigehl T, Wall A, et al. Cell tagging with clinically approved iron oxides: feasibility and effect of lipofection, particle size, and surface coating on labeling efficiency. Radiology. 2005; 235(1):155. e61.

24. Berman SC, Galpoththawela C, Gilad AA, Bulte JW, Walczak P. Longterm MR cell tracking of neural stem cells grafted in immunocompetent versus immunodeficient mice reveals distinct differences in contrast between live and dead cells. Magn Reson Med. 2011;65(2):564-574.

25. Walczak P, Kedziorek DA, Gilad AA, Barnett BP, Bulte JW. Applicability and limitations of MR tracking of neural stem cells with asymmetric cell division and rapid turnover: the case of the shiverer dysmyelinated mouse brain. Magn Reson Med. 2007;58(2):261-269.

26. $\mathrm{Hu} \mathrm{SL}, \mathrm{Lu} \mathrm{PG}, \mathrm{Zhang} \mathrm{LJ}$, et al. In vivo magnetic resonance imaging tracking of SPIO-labeled human umbilical cord mesenchymal stem cells. J Cell Biochem. 2012;113(3):1005-1012.

27. Politi LS, Bacigaluppi M, Brambilla E, et al. Magnetic-resonance-based tracking and quantification of intravenously injected neural stem cell accumulation in the brains of mice with experimental multiple sclerosis. Stem Cells. 2007;25(10):2583-2592.

28. McAteer MA, Sibson NR, von Zur Muhlen C, et al. In vivo magnetic resonance imaging of acute brain inflammation using microparticles of iron oxide. Nat Med. 2007;13(10):1253-1258.

29. Terrovitis J, Stuber M, Youssef A, et al. Magnetic resonance imaging overestimates ferumoxide-labeled stem cell survival after transplantation in the heart. Circulation. 2008;117(12):1555-1562.

30. Ohtaki H, Ylostalo JH, Foraker JE, et al. Stem/progenitor cells from bone marrow decrease neuronal death in global ischemia by modulation of inflammatory/immune responses. Proc Natl Acad Sci U S A. 2008;105(38):14638-14643.

31. Moloney TC, Dockery P, Windebank AJ, Barry FP, Howard L, Dowd E. Survival and immunogenicity of mesenchymal stem cells from the green fluorescent protein transgenic rat in the adult rat brain. Neurorehabil Neural Repair. 2010;24(7):645-656.

32. Pawelczyk E, Jordan EK, Balakumaran A, et al. In vivo transfer of intracellular labels from locally implanted bone marrow stromal cells to resident tissue macrophages. PLoS One. 2009;4(8):e6712.

33. Winter EM, Hogers B, van der Graaf LM, Gittenberger-de Groot AC, Poelmann RE, van der Weerd L. Cell tracking using iron oxide fails to distinguish dead from living transplanted cells in the infarcted heart. Magn Reson Med. 2010;63(3):817-821.

34. Hung TC, Suzuki Y, Urashima T, et al. Multimodality evaluation of the viability of stem cells delivered into different zones of myocardial infarction. Circ Cardiovasc Imaging. 2008;1(1):6-13.

35. Park KI, Teng YD, Snyder EY. The injured brain interacts reciprocally with neural stem cells supported by scaffolds to reconstitute lost tissue. Nat Biotechnol. 2002;20(11):1111-1117.

36. Richardson TP, Peters MC, Ennett AB, Mooney DJ. Polymeric system for dual growth factor delivery. Nat Biotechnol. 2001;19(11): 1029-1034.

37. Liu YP, Seçkin H, Izci Y, Du ZW, Yan YP, Başkaya MK. Neuroprotective effects of mesenchymal stem cells derived from human embryonic stem cells in transient focal cerebral ischemia in rats. J Cereb Blood Flow Metab. 2009;29(4):780-791.

38. Song YS, Lee HJ, Park IH, Kim WK, Ku JH, Kim SU. Potential differentiation of human mesenchymal stem cell transplanted in rat corpus cavernosum toward endothelial or smooth muscle cells. International Journal of Impotence Research. 2007;19(4):378-385. 
International Journal of Nanomedicine

Dovepress

\section{Publish your work in this journal}

The International Journal of Nanomedicine is an international, peerreviewed journal focusing on the application of nanotechnology in diagnostics, therapeutics, and drug delivery systems throughou the biomedical field. This journal is indexed on PubMed Central, MedLine, CAS, SciSearch ${ }^{\circledR}$, Current Contents ${ }^{\circledR} /$ Clinical Medicine,
Journal Citation Reports/Science Edition, EMBase, Scopus and the Elsevier Bibliographic databases. The manuscript management system is completely online and includes a very quick and fair peer-review system, which is all easy to use. Visit http://www.dovepress.com/ testimonials.php to read real quotes from published authors.

Submit your manuscript here: http://www.dovepress.com/international-journal-of-nanomedicine-journal 